\title{
Effects of moisture content on coal analysis using laser-induced breakdown spectroscopy is
}

\author{
Mengyuan Chen a, Tingbi Yuan ${ }^{\mathrm{a}, \mathrm{b}}$, Zongyu Hou ${ }^{\mathrm{a}, \mathrm{b}}$, Zhe Wang a,*, Yun Wang ${ }^{\mathrm{c}, *}$ \\ a State Key Lab of Power Systems, Department of Thermal Engineering, Tsinghua-BP Clean Energy Center, Tsinghua University, Beijing 100084, China \\ ${ }^{\mathrm{b}}$ China Guodian Science and Technology Research Institute, Nanjing 100034, China \\ c Department of Mechanical and Aerospace Engineering, The University of California, Irvine, CA, 92697-3975, United States
}

\section{A R T I C L E I N F O}

\section{Article history:}

Received 14 March 2015

Accepted 14 August 2015

Available online 20 August 2015

\section{Keywords:}

Moisture

Coal

Laser-induced breakdown spectroscopy

LIBS

\begin{abstract}
A B S T R A C T
Laser-induced breakdown spectroscopy (LIBS) is regarded as a very promising technique for fast or online coal analysis. However, the analytical performance is greatly influenced by its moisture content. In the present work, the effects of moisture content variations on the properties of the laser-induced plasma and its spectral signals were investigated using the same coal samples mixed with different moisture contents. Plasma morphology and spatially resolved spectra were also obtained to further investigate the effects, and the mechanism of the effects was also discussed. Results showed that most of the spectral line intensities decreased as the moisture content increased, even including those of $\mathrm{H}$ and $\mathrm{O}$. Seen from the spatially resolved spectra, the profile of $\mathrm{H}$ intensity over the height of plasma showed a higher peak position with increasing moisture content, and the height of the peak of the $\mathrm{H}$ intensity profile was slightly higher than those of other elements such as $\mathrm{C}$ and Al. The laser ablation process and mechanism underlying the effects of moisture content were proposed as following: part of the moisture was evaporated first under laser radiation and ablated earlier than those of other coal materials. Consequently, the outside layer of the laser-induced plasma was mostly from the dissociation of moisture. Given the earlier evaporation of moisture, part of the energy was used to dissociate and ionize the surrounding water vapor or even reflected by the splashed particle caused by fast expanding moisture, thereby shielding the further absorption of laser energy to the solid coal material. This phenomenon resulted in less coal mass being actually ablated into the plasma with increasing moisture content, hence emitting smaller line intensities. On the other hand, the decrease in $\mathrm{H}$ line intensity may be caused by the fact that these elements were pushed to the outside cooler layer.
\end{abstract}

(c) 2015 Elsevier B.V. All rights reserved.

\section{Introduction}

Online or fast coal analysis is of great necessity for coal pricing and combustion or gasification optimization for power, coal chemical processing, and coal mine industries. Traditional chemical processes usually take about more than $10 \mathrm{~h}$ to finish both ultimate and proximate analyses, so online or fast analysis is clearly impossible. Prompt gamma neutron activation analyzer (PGNAA) is a technique which can realize online and multi-elemental analysis. However, it has several decisive disadvantages which have severely restricted its application: the machine itself and its operation cost are very expensive, and its neutron source presents potential health hazards and has strict regulatory demands [1]. As a relative inexpensive and non-harmful technique, laser-induced breakdown spectroscopy (LIBS) has been regarded as a potential leading analytical technology for applications with online or

\footnotetext{
it Selected Paper from the 8th International Conference on Laser Induced Breakdown Spectroscopy (LIBS 2014), Beijing (China), 8-12 September 2014.

* Corresponding authors.

E-mail addresses: zhewang@tsinghua.edu.cn (Z. Wang), yunw@uci.edu (Y. Wang).
}

fast analysis demands, including coal analysis, because of its advantages of fast and multi-elemental analyses, with minimal or no sample preparation [2].

A series of studies have been conducted on LIBS applications for coal analysis, including elemental (ultimate) analysis [3-5] and coal property (proximate) analysis [6,7]. Wallis et al. [3] measured the elemental composition of $\mathrm{Si}, \mathrm{Al}, \mathrm{Fe}, \mathrm{Ca}, \mathrm{Mg}, \mathrm{Na}$ and $\mathrm{Li}$ [4] and Yuan et al. [5] analyzed the carbon content. Dong et al. [6] measured the volatile matter content. Yuan et al. [7] analyzed the ash content, volatile content and calorific value. In addition, all the coal samples used were air-dried. Other studies have improved the accuracy or precision of quantitative analysis for coal samples, including experimental parameter optimization [8], sample preparation progress [9] and data processing methods [10-12].

As mentioned above, the sample used in most of these investigations was air-dried coal, which has a relatively stable moisture content, thus the effects of moisture content variations were ignored. However, in on-site or online measurement, the moisture content of coal samples may vary in a wide range. Gaft et al. [13] used coal samples directly from collieries, and found that large moisture content variations could lead to 
substantial alterations in LIBS spectra, as well as large errors in ash evaluation. Moreover, they found a gross correlation between moisture and spectra changes upon evaluating coal moisture, and made further corrections for ash evaluation. Body and Chadwick [14] analyzed lignite using LIBS, and found that samples with lower moisture content require less laser energy to obtain optimum signals. For online coal analysis, the effects of moisture variations should be quantitatively determined.

To date, knowledge on the mechanism of the effects of moisture content on LIBS analysis is lacking, and relevant work only studied the influence of moisture content variations primarily. In the present work, we attempted to investigate the effects of moisture content variations on the spectra and plasma morphology of LIBS systematically. Moreover, we established a model on the laser-material interaction process to explain the mechanism underlying these effects. All these investigations will contribute to our future quantitative analyses.

\section{Experimental}

The experimental setup is illustrated in Fig. 1. The laser source employed was a Q-switched Nd:YAG pulse laser with a wavelength of $1064 \mathrm{~nm}$ and a pulse duration of 5-7 ns. The laser energy was optimized to $90 \mathrm{~mJ} /$ pulse, and the corresponding excitation fluence was about $71.6 \mathrm{~J} / \mathrm{cm}^{2}$ with the spot size being about $0.00126 \mathrm{~cm}^{2}$.

Plasma-emitted radiation was collected by two detection systems. System 1 was used to investigate the integrated spectrum and time evolution of plasma temperature, electron density and line intensity. System 2 was used to obtain the spatially resolved spectrum of certain lines and the image of the plasma simultaneously. System 1 was composed of fibers, six spectrometers, and charged-coupled device (CCD) detectors. Six spectrometers and CCD detectors covered an overall range (nm) from 190 to 309,309 to 460,460 to 588,588 to 692,692 to 844 , and 844 to 1041 respectively, with a nominal resolution of $0.07 \mathrm{~nm}$ and fixed integration time of $1 \mathrm{~ms}$. The delay time of system 1 was fixed at $1 \mu$ s to obtain the integrated spectrum and varied from $0 \mu$ s to $4 \mu$ s for time evolution analyses. The emission was collected by the fiber connected to the entrance port of the spectrometer. System 2 was composed of an adjustable spectrometer and an intensified CCD detector covering a spectral range from $180 \mathrm{~nm}$ to $700 \mathrm{~nm}$. The integration time of system 2 was fixed at 100 ns with the delay time varying from $0 \mu$ s to $1 \mu$ s for both the spatially resolved spectrum and plasma image investigation. A vertical slit in the front of the spectrometer was adjusted to allow the central part of the plasma emission to enter the spectrometer by setting it over against the middle of the plasma. The slit width was fixed at $20 \mu \mathrm{m}$, whereas the maximum width of the plasma was about $2 \mathrm{~mm}$. To obtain the spectrum intensity at different heights, the spectrum was divided into 10 equal parts along the plasma height (i.e. the y axis).

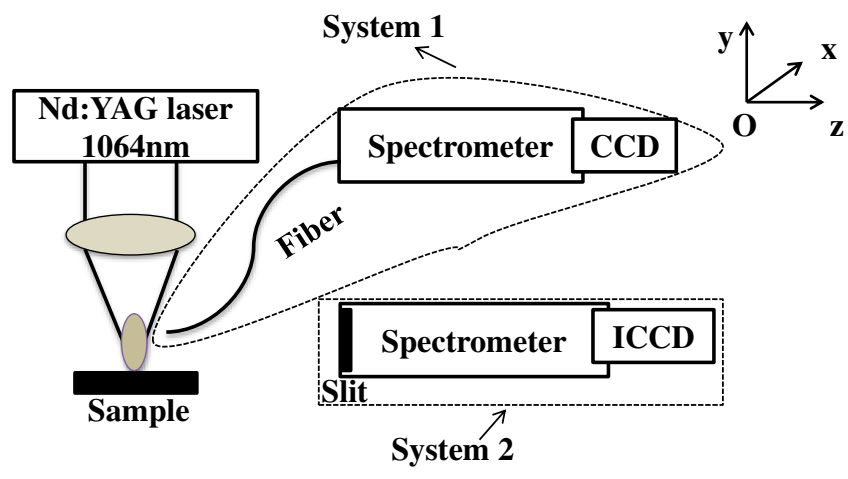

Fig. 1. Schematic presentation of the experimental setup.
Only one type of the raw coal was studied and it was provided by Huadian Power International Ltd., China. Its composition on an air-dried basis is shown in Table 1.

To obtain samples with different moisture contents, the raw coal sample was mixed with different amounts of deionized water and then stirred manually using a mortar and pestle. In our experiment, the coal sample was mixed with a certain moisture content and then was pressed into three pellets with the same moisture content. One was used for LIBS analysis, and the other two were used for moisture analysis by an industrial moisture analyzer. Deviations in the moisture measurement were minimized because LIBS analysis and moisture measurements were carried out simultaneously. The two pellets used for moisture analysis were mashed into small pieces and then divided into three or four parts for moisture measurement. Thus, three or four moisture data could be obtained for one sample. The deviations of the data met the national standard, which verified that the sample preparation method could ensure homogeneous distribution of water. The moisture content of the samples prepared by this method in our experiment varied from $1.19 \%$ to $22.25 \%$.

The sample was placed on an auto-controlled X-Z translation stage, and the 80 spectra collected from different positions on each pellet were averaged to minimize the unintended experimental fluctuations. The raw intensity of each line was pretreated by segmental normalization, which has been proven that can reduce the relative standard deviations (RSDs) and benefit quantitative analysis in our previous work [15].

\section{Results and discussion}

The integrated and time evolution of the line intensity, spatially resolved spectra, ablated mass, and plasma morphology were analyzed using samples with different moisture contents to investigate the mechanism underlying the effects of moisture content on LIBS analysis.

\subsection{Integrated line intensity}

The spectra obtained from coal samples with relatively higher $\left(\mathrm{M}_{\mathrm{h}}, 22.25 \%\right)$ and lower $\left(\mathrm{M}_{\mathrm{l}}, 1.19 \%\right)$ moisture contents via system 1 are shown in Fig. 2. Most of the line intensities and background noise from samples with higher moisture content were lower than those from samples with lower moisture content.

To further demonstrate the dependence of line intensity on moisture contents, nine samples with different moisture contents were analyzed using LIBS further. Moreover, the linear correlation coefficients between the different line intensities and moisture contents were calculated. The liner correlation coefficient $r$ was calculated using the following equation:

$r=\frac{\sum_{i=1}^{n}\left(M_{i}-\overline{M_{i}}\right)\left(\left(I_{i}-\overline{I_{i}}\right)\right.}{\sqrt{\sum_{i=1}^{n}\left(M_{i}-\bar{M}_{i}\right)^{2} \sum_{i=1}^{n}\left(\left(I_{i}-\overline{I_{i}}\right)^{2}\right.}}$

where $n$ is the sample number, $M_{i}$ is the moisture content of the sample, $I_{i}$ is the intensity of the characteristic line, and $\overline{M_{i}}$ and $\overline{I_{i}}$ was the average of $M_{i}$ and $I_{i}$ respectively. In addition, only the correlation coefficients for the lines whose intensity was higher than 1000 a.u. and absolute value of correlation coefficients were larger than 0.2 were demonstrated.

Table 1

Composition of the raw coal sample on an air-dried basis.

\begin{tabular}{lllll}
\hline Element & $\mathrm{C}(\%)$ & $\mathrm{N}(\%)$ & $\mathrm{H}(\%)$ & Full S (\%) \\
\hline Content & 74.67 & 1.03 & 4.61 & 0.61 \\
\hline
\end{tabular}




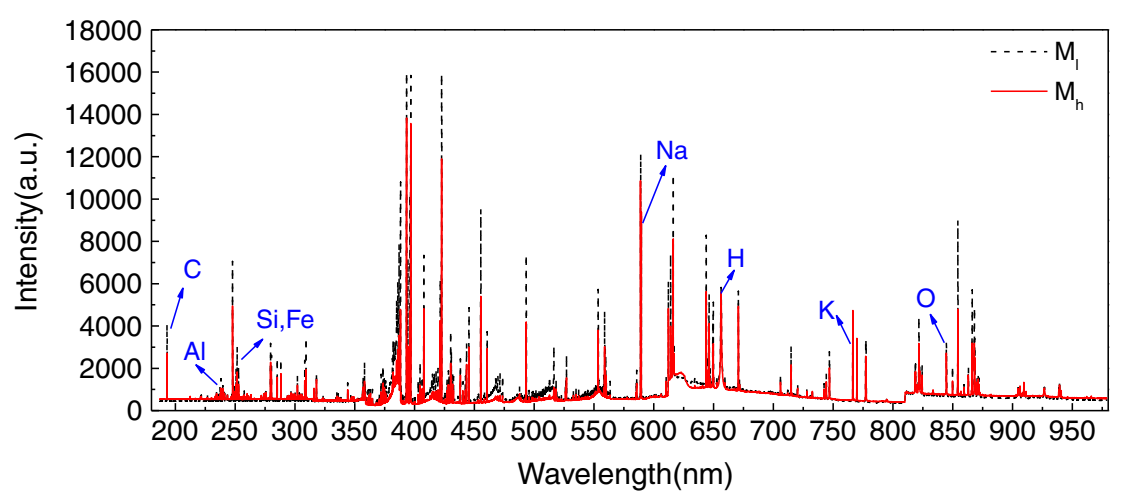

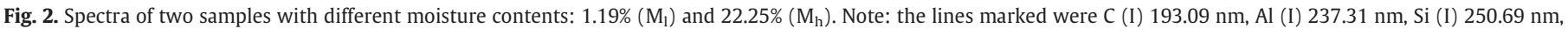
Fe (I) $252.28 \mathrm{~nm}, \mathrm{Na}$ (I) $589.00 \mathrm{~nm}, \mathrm{H}$ (I) $656.25 \mathrm{~nm}, \mathrm{~K}$ (I) $769.90 \mathrm{~nm}$ and O (I) $844.68 \mathrm{~nm}$, respectively.

As shown in Fig. 3, the intensity of most elements in coal, including the major elements ( $\mathrm{C}, \mathrm{H}, \mathrm{O}$, and $\mathrm{N}$ ) and minor elements ( $\mathrm{Si}, \mathrm{Al}$, and $\mathrm{Fe}$ ), was negatively correlated with the moisture content. In addition, only the minor or trace alkali elements ( $\mathrm{Na}$ and $\mathrm{K}$ ) had positive coefficients. All the lines of the alkaline elements available in the present work (K (I) $766.49 \mathrm{~nm}, \mathrm{~K}$ (I) $769.90 \mathrm{~nm}$, Na (I) $589.00 \mathrm{~nm}$, and $\mathrm{Na}$ (I) $588.59 \mathrm{~nm}$ ) showed positive correlations. The increase in the ash content of coal samples had positive effects on most line intensities, which would entangle with the signal changes because of moisture content variations. Although the reason for the positive correlation remains unknown, the special correlation between the line intensity of alkali elements with moisture content might provide some useful clue to find out whether the line intensity changes come from moisture content variations or from ash content variation for quantitative analysis of coal using LIBS.

As shown in Fig. 4, for most elements, including C, $\mathrm{H}, \mathrm{O}, \mathrm{Si}$, Fe, and $\mathrm{Al}$, negative linear correlations were found between their line intensities and moisture contents. A negative correlation between the line intensities of $\mathrm{C}, \mathrm{Si}, \mathrm{Fe}$, and $\mathrm{Al}$ and moisture content was reasonable given that high moisture content in the coal samples resulted in lower levels of these elements because the analytic sample was combined of less raw coal material and more water content. However, surprisingly, the correlation between the moisture content and $\mathrm{H}$ or $\mathrm{O}$ was also negative; the sample should have higher $\mathrm{H}$ and $\mathrm{O}$ elemental concentrations. The negative linear correlation between the line intensities of these elements and moisture content would be applied to provide other important information in calculating the moisture content and correcting the calculations of other elements' concentration.

The aforementioned results indicated that the decrease in the spectra intensity was not simply caused by the reduction in

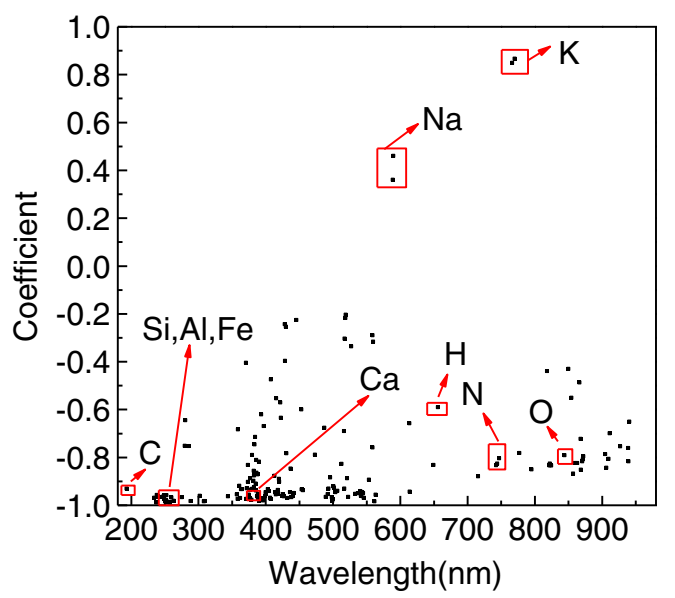

Fig. 3. The correlation coefficients of the different line intensities versus moisture content. concentration. Therefore, the plasma properties, including plasma temperature $(T)$, electron density $\left(n_{e}\right)$, and total number density, were further investigated in the following section.

\subsection{Plasma property}

Two samples of different moistures [1.19\% $\left(\mathrm{M}_{1}\right)$ and $\left.22.25 \%\left(\mathrm{M}_{\mathrm{h}}\right)\right]$ were used to compare the plasma temperature and electron density. As described above, the delay time of system 1 was varied from $0 \mu$ s to $4 \mu \mathrm{s}$ for time evolution analyses of temperature and electron density. In this study, the temperature was calculated from Boltzmann plots using five Si lines (212.41, 243.44, 250.68, 251.59, and $288.16 \mathrm{~nm}$ ). The electron number density was calculated from the full width at half maximum of the $N(\mathrm{I})$ line at $746.83 \mathrm{~nm}, \Delta \lambda_{1 / 2}$ with the following equation [16]:

$\Delta \lambda_{1 / 2}=2 \omega n_{e} / 10^{16}$

where $\omega$ is the electron effects parameter, which can be obtained from [17]. The calculated values of the electron density revealed that the McWhirter criterion was satisfied in the experiments, partially validating the LTE assumption.

As shown in Fig. 5, the plasma temperature was nearly the same for the two samples at all delay times, except for the very early stage. In terms of the electron density, a higher value was noted for the sample with higher moisture content at the beginning but it decayed faster and then became almost the same as that of the sample with lower moisture content. The electron densities of the two samples were almost the same after $1 \mu$ s. The higher electron density for coal sample with higher moisture content at the earlier stage may come from the dissociation and ionization of easily evaporated moisture. The almost same plasma temperature and electron density indicated that the decrease in integrated line intensities should come from the decrease in the total number density of the measured elements or real ablated mass.

The total number density inside the plasma is almost impossible to measure. Researchers usually use the ablated mass to indicate the total number density. However, the ablated mass of the coal sample is also very difficult to directly measure because the mass ablated by each laser pulse is too low to measure by the balance. Therefore, we determined the ablated mass through the volume of the ablated crater by one laser pulse indirectly. In the present work, the crater size was estimated from the photos taken by an optical microscope, as shown in Fig. 6.

By assuming the crater was shaped like a cylinder, its volume $(V)$ can be estimated by the following equation:

$V=h \pi R^{2}$ 

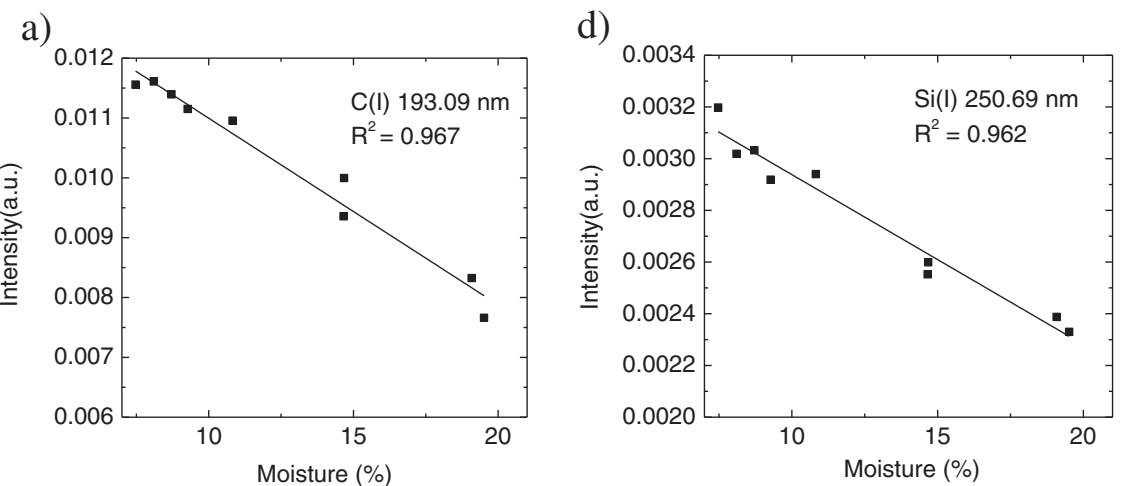

b)
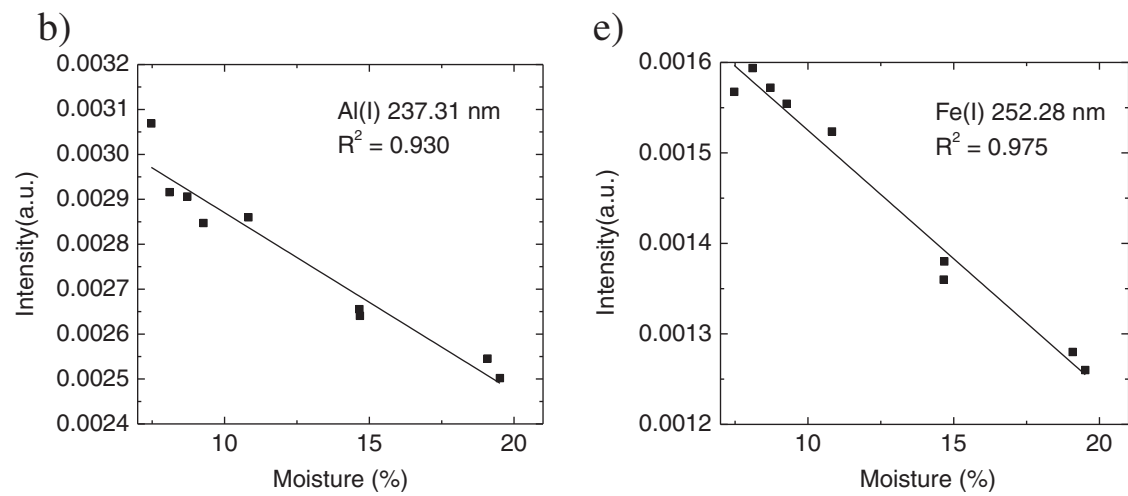

f)
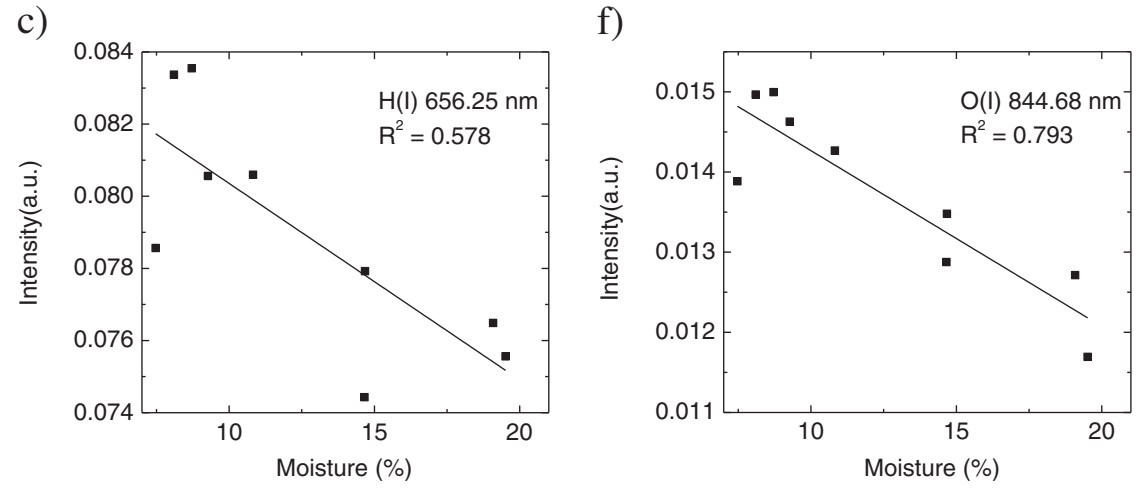

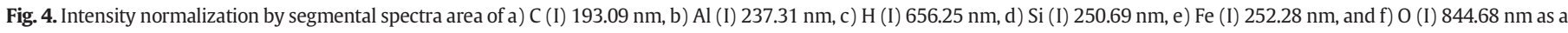
function of the moisture content.

where $h$ is the depth of the crater, and $R$ is the radius of the crater's surface, which can both be estimated from the photos. In addition, the total coal sample mass was measured by an analytical balance,

a)

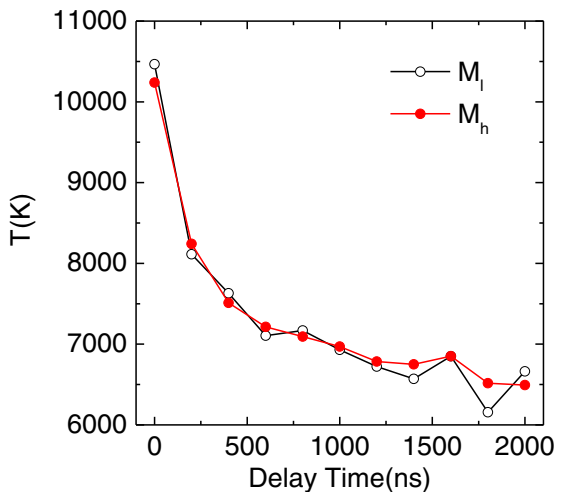

and the density of the coal sample, $\rho$, was estimated using the total coal sample mass divided by the estimated pellet volume. The estimated ablated mass in the two conditions is shown in

b)

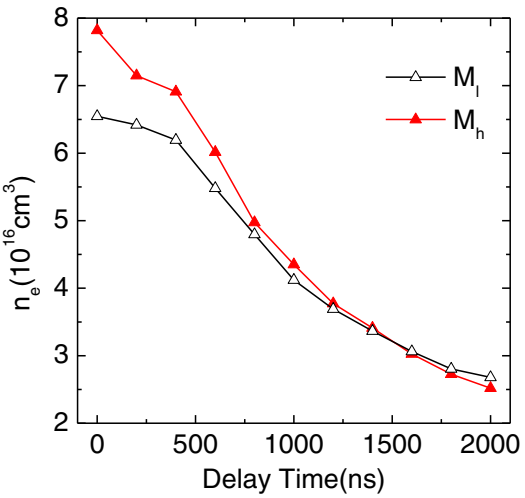

Fig. 5. Time evolution of a) plasma temperature and b) electron density for two coal samples with different moisture contents. 
a) $\mathrm{M}_{1}$

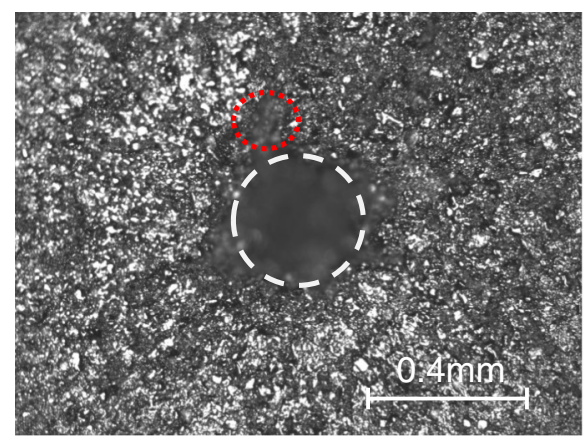

b) $\mathrm{M}_{\mathrm{h}}$

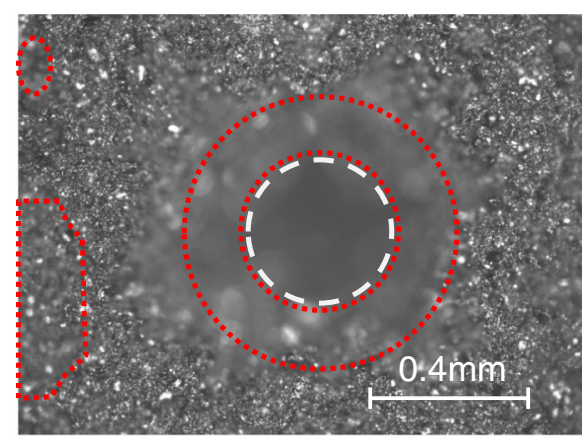

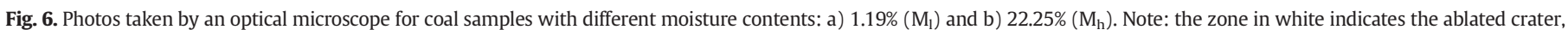

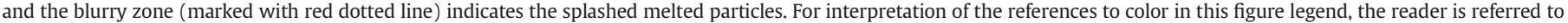
the web version of this article.

Table 2, as well as the calculated dry-based ablated mass using the following equation:

$M_{d}=M_{t} \times(1-W \%)$

where $M_{d}$ is the calculated dry-based ablated mass, $M_{t}$ is the total ablated mass, and $W \%$ is the moisture content.

The ablated mass (even the calculated dry-based mass) of the coal sample with higher moisture content was higher than that of the coal sample with lower moisture content. Together with the results of plasma temperature and electron density shown in Section 3.3, these findings should lead to higher line signal intensities for coal samples with higher moisture contents, thereby contradicting our observations in our experiment and in other experiments [18-21]. By observing the ablated coal samples carefully, we found more splashed particles attached on the surface for coal samples with higher moisture contents, as shown in Fig. 6 (the blurry zone marked with red dotted lines). Considering that the mass of these splashed particles was included in the ablated mass (or dry-based ablated mass) estimation, the real mass ablated into plasma for signal emission contribution was possibly lower for coal samples with higher moisture contents than that for coal samples with lower moisture contents. Therefore, the decrease in the spectral signals could be explained by the decrease in real dry-based ablated mass with increasing moisture content.

\subsection{Plasma morphology, spectra evolution, and spatially resolved spectra}

To further understand the effects of moisture content on the LIBS analytic performance, as well as its mechanism, plasma image, spectra evolution, and spatially resolved spectra were also investigated.

The plasma image with different delay times for coal samples with lower $\left(\mathrm{M}_{1}\right)$ and higher $\left(\mathrm{M}_{\mathrm{h}}\right)$ moisture contents is shown in Fig. 7. For coal samples with higher moisture content, the plasma size was smaller and the brightness was lower, except for the early stage. In addition, the plasma images were more stable for coal samples with lower moisture content than those for coal samples with higher ones, which possibly resulted from the fact that more splashed melted particles passed through the plasma. Furthermore, this finding explained the larger RSDs for coal samples with higher moisture content, as shown in Fig. 11.

Table 2

Results of the estimated ablation mass.

\begin{tabular}{llll}
\hline Sample & Moisture content $(\%)$ & Ablated mass $(\mu \mathrm{g})$ & Ablated dry-based mass $(\mu \mathrm{g})$ \\
\hline $\mathrm{M}_{\mathrm{h}}$ & 12.003 & 0.237 & 0.208 \\
$\mathrm{M}_{\mathrm{l}}$ & 3.710 & 0.191 & 0.184 \\
\hline
\end{tabular}

The evolutions of intensity of the lines $H$ (I) $656.25 \mathrm{~nm}$, C (I) $193.09 \mathrm{~nm}$, and Al (I) $237.31 \mathrm{~nm}$ over time are shown in Fig. 8. The data were obtained by system 1 with the delay time varied from $0 \mu$ s to $4 \mu$ s and the gate time fixed at $1 \mu$ s. The intensity of $\mathrm{H}$ for coal samples with higher moisture $\left(\mathrm{M}_{\mathrm{h}}\right)$ was higher at the initial time $(<750 \mathrm{~ns})$, but decayed faster and became lower than that for coal samples with lower moisture $\left(\mathrm{M}_{\mathrm{l}}\right)$ thereafter. By contrast, the intensities of $C$ and $\mathrm{Al}$ for coal samples with higher moisture coal sample $\left(\mathrm{M}_{\mathrm{h}}\right)$ were always lower than those for lower ones $\left(\mathrm{M}_{1}\right)$, which was also observed for the line intensities of most other elements, such as Si and Fe. For coal samples with higher moisture content, more water was dissociated and ionized during the earlier stage of the laser-induced plasma lifetime. Moisture evaporated more easily compared with other coal materials and more moisture were evaporated in coal samples with higher moisture content, leading to increased moisture dissociation and ionization during the earlier stage of laser radiation. Given that elements dissociated from moisture ( $\mathrm{H}$ and $\mathrm{O}$ ) were pushed to the outer cooler layer of the plasma, the signal emitted by this cooler layer became smaller, resulting in a faster decline of $\mathrm{H}$ line intensity. At the later stage, the $\mathrm{H}$ line intensity mainly came from the $\mathrm{H}$ elements in the inner part of the plasma, which was resulted from other coal materials instead of moisture, thereby leading to an even smaller $\mathrm{H}$ line intensity for coal samples with higher moisture content. Considering that less coal material was ablated, the line intensities of $\mathrm{C}$ and $\mathrm{Al}$ decreased.

The spatially resolved intensities of $\mathrm{H}, \mathrm{C}$, and $\mathrm{Al}$ are shown in Fig. 9. Both the height of the peak of the profile of $\mathrm{H}$ for samples with higher moisture content (about $1.2 \mathrm{~mm}$ ) and lower moisture content $(0.8 \mathrm{~mm})$ were always higher than those of $\mathrm{C}$ and $\mathrm{Al}$ (about $0.7 \mathrm{~mm}$ ). This finding supported our assumption that water vapor was easily evaporated, dissociated, and ionized than other materials; therefore, the $\mathrm{H}$ element from moisture was pushed by the other ablated materials to a higher position.

Moreover, the profile of $\mathrm{H}$ intensity over the height of plasma showed a higher peak position with increasing moisture content, whereas the height of the peak for $\mathrm{C}$ and $\mathrm{Al}$ remained the same. This phenomenon also supported our conclusion. Given the higher moisture content in the coal samples, more moisture was evaporated and dissociated at the early stage of laser radiation, resulting in a thicker layer from the dissociation of moisture and a higher peak position.

In addition, the peak intensity of $\mathrm{H}$ of coal samples with higher moisture content was higher at the beginning and then decreased faster to an even lower value than that of coal samples with lower moisture content. By contrast, the peak intensities of $\mathrm{C}$ and $\mathrm{Al}$ were always lower for coal samples with higher moisture content. These findings were consistent with the plasma image shown in Fig. 7 and line intensity in Fig. 8. 


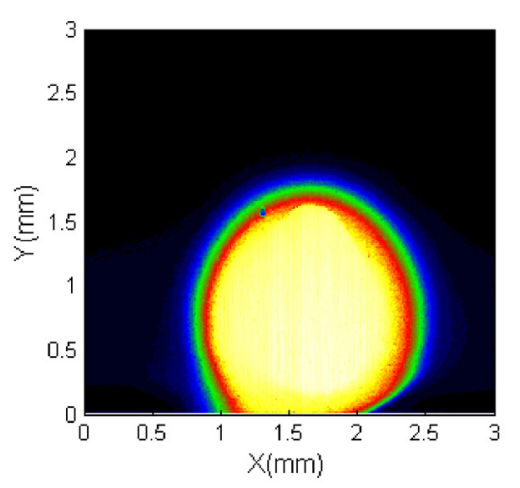

1a) $\mathrm{T}_{\mathrm{d}}=0 \mathrm{~ns}$

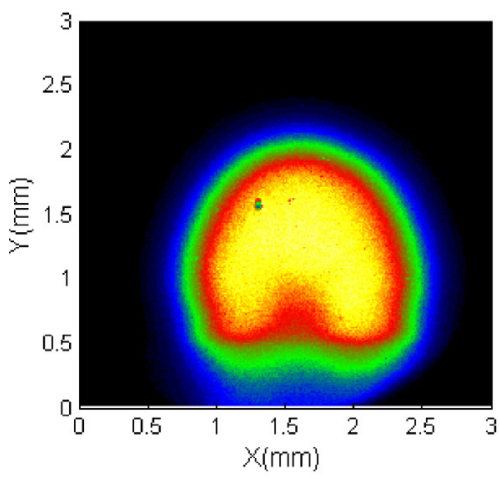

1b) $\mathrm{T}_{\mathrm{d}}=300 \mathrm{~ns}$

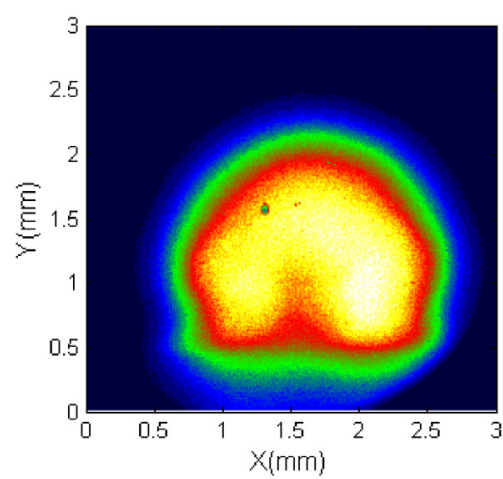

1c) $\mathrm{T}_{\mathrm{d}}=700 \mathrm{~ns}$

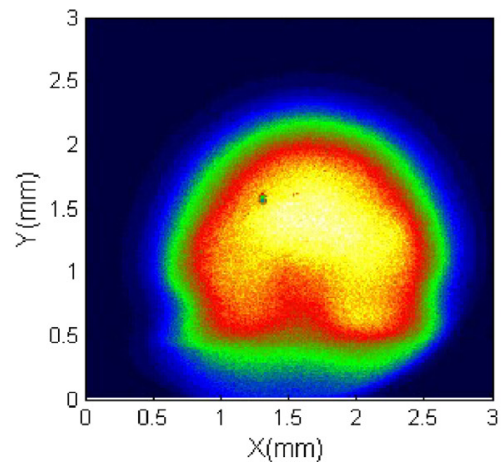

1d) $\mathrm{T}_{\mathrm{d}}=800 \mathrm{~ns}$

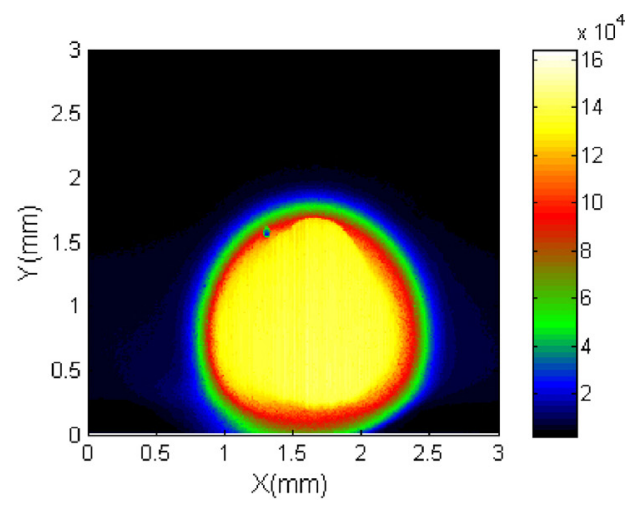

2a) $T_{d}=0 \mathrm{~ns}$

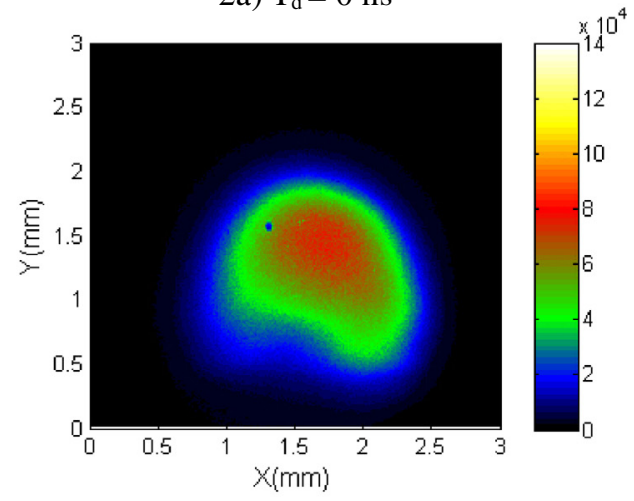

2b) $\mathrm{T}_{\mathrm{d}}=300 \mathrm{~ns}$

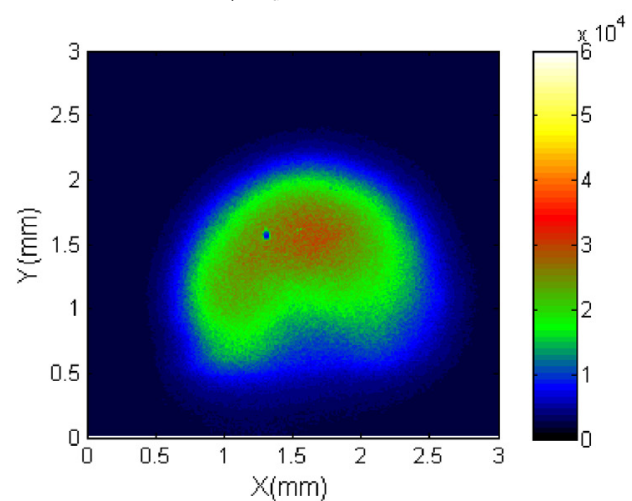

2c) $\mathrm{T}_{\mathrm{d}}=700 \mathrm{~ns}$

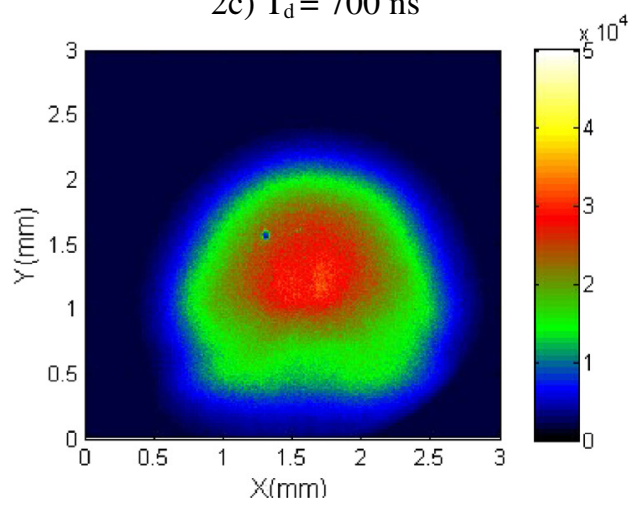

2d) $\mathrm{T}_{\mathrm{d}}=800 \mathrm{~ns}$

Fig. 7. Plasma images of samples with 1) lower moisture content (1.19\%, $\left.\mathrm{M}_{1}\right)$ and 2$)$ higher moisture content (22.25\%, $\left.\mathrm{M}_{\mathrm{h}}\right)$ at different delay times.

\subsection{Possible effects mechanism}

Based on the experimental results, the mechanism of laser-material interaction process in coal samples with various moisture contents is shown in Fig. 10 as follows based on Noll's proposition [22]: a pulsed laser beam was focused onto the surface of coal sample as shown in Fig. 10a, and radiation energy was locally coupled into the material. The material started to evaporate accompanied with the splashed 
a)

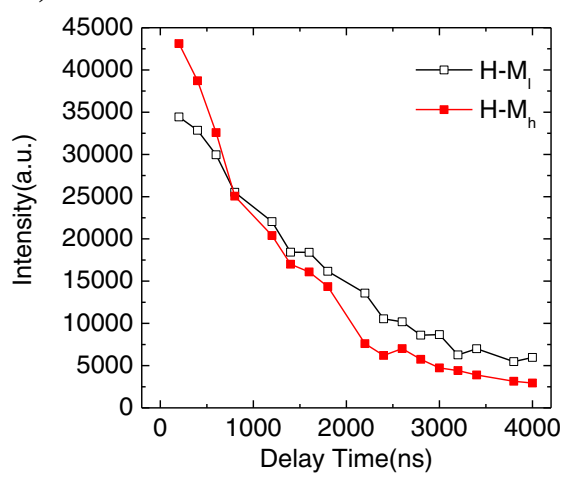

b)

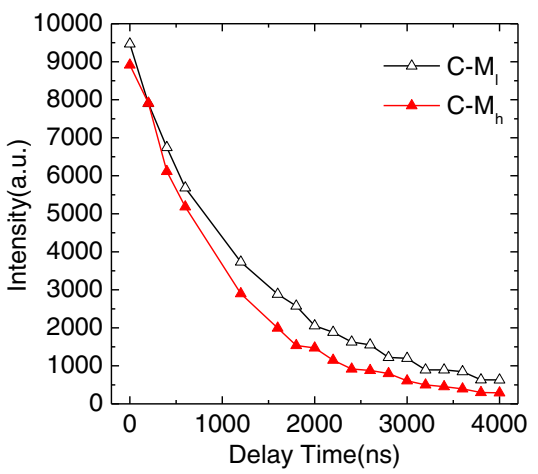

c)

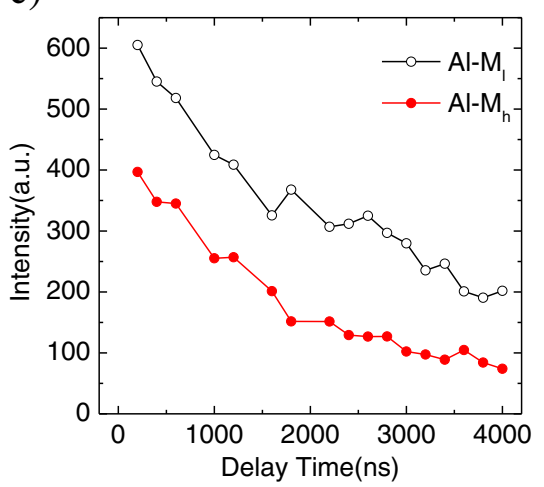

Fig. 8. Line intensity evolution of H (I) $656.25 \mathrm{~nm}, \mathrm{C}$ (I) $193.09 \mathrm{~nm}$, and $\mathrm{Al}$ (I) $237.31 \mathrm{~nm}$.

melted particles. The moisture evaporated from the coal sample (Fig. 10.b) earlier than the other material in coal. Subsequently, a mixed zone was formed by the water vapor from the upper region and the coal vapor from the lower region (Fig. 10.c). The plasma was generated within the coal-water mixed vapor and surrounding gas atmosphere (Fig. 10.d), leading to the excitation of the coal constituents and their spontaneous emission of radiation. The plasma decayed and emitted element-specific radiation (Fig. 10.e-g). The upper location of water vapor caused its corresponding distribution in the plasma, which was consistent with the results in Fig. 9 that there is a higher peak position of the $\mathrm{H}$ for samples with high moisture content. At the initial time (before $1 \mu \mathrm{s}$ ), water vapor was partly excited leading to higher $\mathrm{H}$ intensity for higher moisture content coal sample $\left(\mathrm{M}_{\mathrm{h}}\right)$ (Fig. 8a). With plasma expansion, the water vapor was pushed upward to the outside cooler layer of the plasma, which did not contribute to the collected spectra at the delay time of 1-2 $\mu$ s, because the collecting fiber in system 1 (Fig. 1) was fixed at the center of the maximum plasma (at around $800 \mathrm{~ns}$ ), and the water emission could not be collected. Consequently, the $\mathrm{H}$ line of $\mathrm{M}_{\mathrm{h}}$ decayed faster. Its integrated intensity, as well as that of $\mathrm{O}$, decreased as the moisture content increased at the delay time of $1 \mu \mathrm{s}$. Similar to the tendency of $\mathrm{H}$ and $\mathrm{O}$, the electron density of $\mathrm{M}_{\mathrm{h}}$ was higher before $1 \mu$ s which was caused by water ionization; its faster decay could be attributed to the water's relatively high electronegativity (about $0.9 \mathrm{eV}$ ), which suggested water vapor scavenged electrons [23].

The process denoted in Fig. 10 is always accompanied with the splashed melted particles. As shown in Fig. 6, evaporation left many gaps in the sample, resulting in a sample with a loose internal structure. Such gaps also made the mass to be easily sprayed by the laser, leading to a larger crater size, and increasing the uncertainty of laser ablation. Thus, for sample with higher moisture content, more masses were sprayed out of the plasma, leading to the higher estimated dry-based ablated mass in Table 1. However, the estimated dry-based ablated mass is just the mass that left the crater, which is not the real mass ablated into plasma for signal emission. At the delay time of $1 \mu \mathrm{s}$, as the plasma temperature and electron density were almost the same for both $\mathrm{M}_{1}$ and $\mathrm{M}_{\mathrm{h}}$, it can be deduced that the decrease of the emission lines in the spectra mainly attributed to the reduction of the real ablated mass into plasma. That is, when high concentration of moisture existed, there was not enough laser energy for the real ablated mass into plasma. The energy lost by water evaporation could be neglected, as estimated by the ablation mass from Table 2, evaporation of moisture in a crater on $\mathrm{M}_{\mathrm{h}}$ required roughly $10^{-5} \mathrm{~mJ}$, which was just a very small portion of the total energy of one laser pulse. Based on the mechanism discussed above, the laser could be largely consumed by the dissociation and ionization of these surrounding water vapor or even reflection by the splashed particle generated by fast expanding moisture. The left laser energy was not enough to excite all the ablated mass generated in the initial time to form plasma, so some of those ablated mass left on the sample surface and was observed as particles in Fig. 6. As a result, the real mass ablated into plasma decreased as moisture content increased, leading to the decrease of line intensity. However, individual elements such as $\mathrm{Na}$, K were positively correlated with moisture content (Fig. 3), maybe because the compound containing $\mathrm{Na}$ and $\mathrm{K}$ was easily soluble in water and existed as ionic condition, which made the excitation of $\mathrm{Na}$ and $\mathrm{K}$ much easier.

In summary, compared with the mechanism in Noll's book [22], the process of the earlier evaporation of moisture was added in the laser-material interaction process for coal samples with high moisture content.

\subsection{RSD, signal to background ratio (SBR), and signal to noise ratio (SNR)}

The RSD, SBR, and SNR using the lines $\mathrm{H}$ (I) $656.25 \mathrm{~nm}$, C (I) $193.09 \mathrm{~nm}$, and $\mathrm{Al}$ (I) $237.31 \mathrm{~nm}$ are shown in Fig. 11. In addition, in calculating the SNR and SBR, the signal was obtained using the integrated area of the spectral peak, the background was calculated as the background area underneath the signal peak, while the noise was defined as the standard deviation of the non-peak area adjacent to the spectral peak.

The RSD, SBR, and SNR using the lines $\mathrm{H}$ (I) $656.25 \mathrm{~nm}$, C (I) $193.09 \mathrm{~nm}$, and $\mathrm{Al}$ (I) $237.31 \mathrm{~nm}$ are shown in Fig. 11. The increase in RSD could be explained as the combination of the following: 1) the unevenness of the sample surface as the moisture content increased; and 2) the evaporation of water generated splashed melted particles, which made the plasma morphology less stable.

The results of RSD, SNR, and SBR demonstrated that higher moisture contents resulted in larger RSD, lower SNR and lower SBR, which were not beneficial to quantitative analysis. From another perspective, the information in this study could be applied in quantitative analysis of the moisture content, carbon content, heat value and ash content.

For a clear comparison, Table 3 summarizes the results of the current work and the related literature.

\section{Conclusion}

In the present work, the effects of moisture content variations on the properties of laser-induced plasma and its spectral signals were studied using the coal samples with various moisture contents. Results indicated that most spectral line intensities, even $\mathrm{H}$ and $\mathrm{O}$ decreased and the RSDs of those lines increased as the moisture content increased. The plasma morphology and spatially resolved spectra were investigated to determine the mechanism of the effects. Part of the moisture evaporated first under laser radiation and ablated earlier than other coal materials, leading to a type of laser energy shield, including surrounding water vapor dissociation, ionization, and splashed particle 


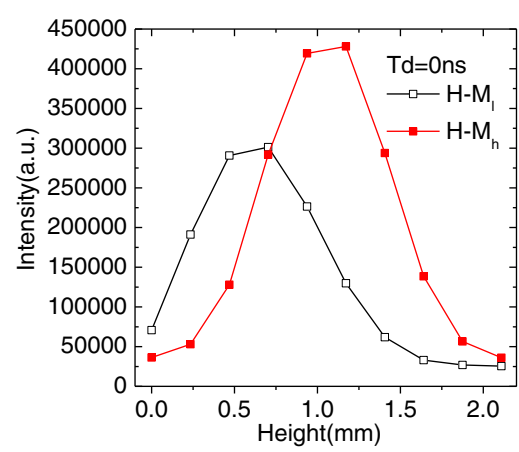

1a) $T_{d}=0 \mathrm{~ns}$

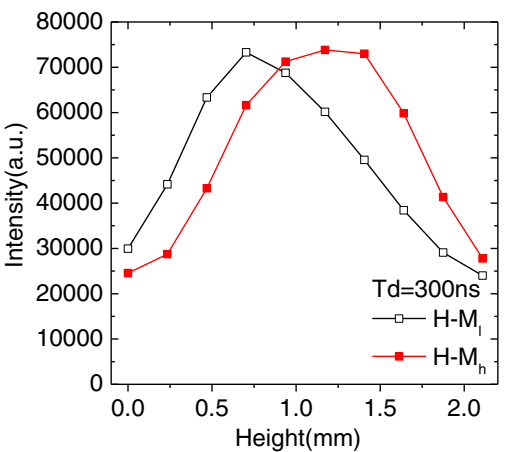

1b) $T_{d}=300 \mathrm{~ns}$

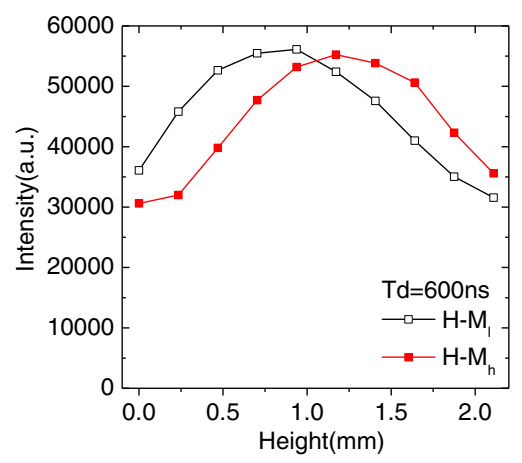

1c) $T_{d}=600 \mathrm{~ns}$

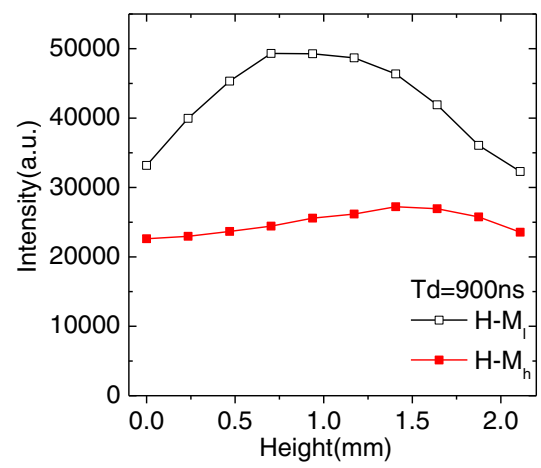

1d) $T_{d}=900 \mathrm{~ns}$

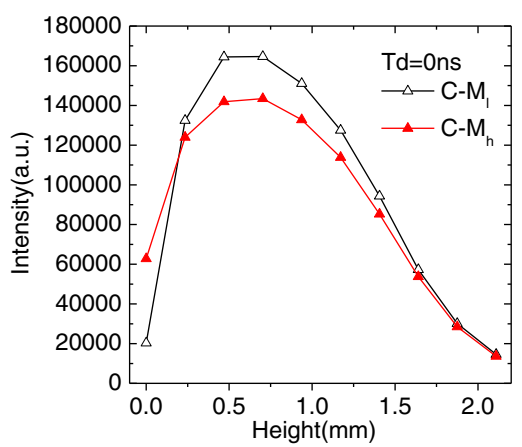

2a) $T_{d}=0 \mathrm{~ns}$

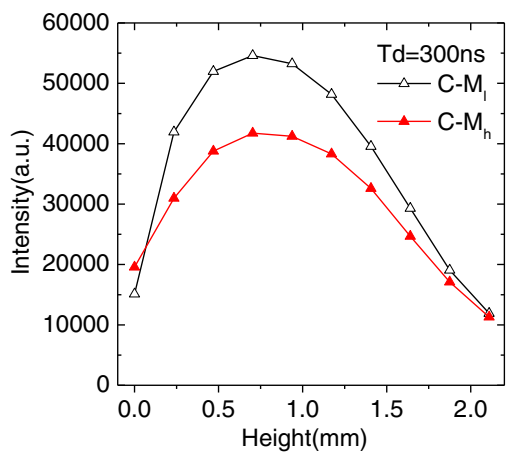

2b) $\mathrm{T}_{\mathrm{d}}=300 \mathrm{~ns}$

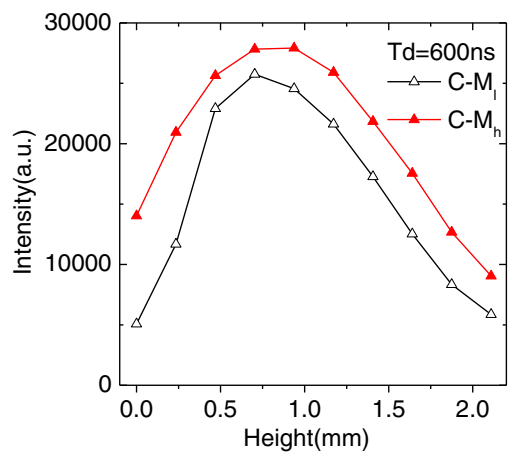

2c) $T_{d}=600 \mathrm{~ns}$

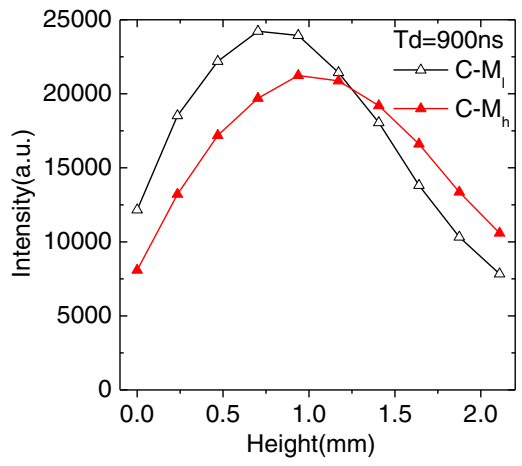

2d) $\mathrm{T}_{\mathrm{d}}=900 \mathrm{~ns}$

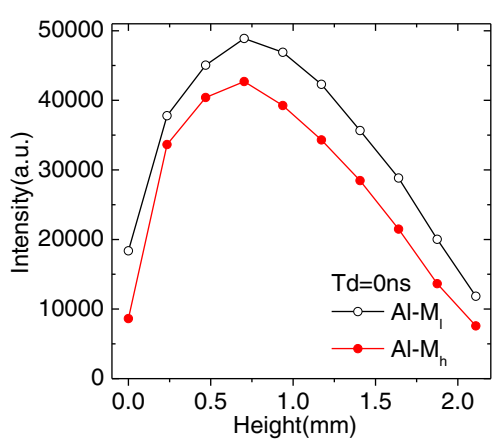

3a) $T_{d}=0 \mathrm{~ns}$

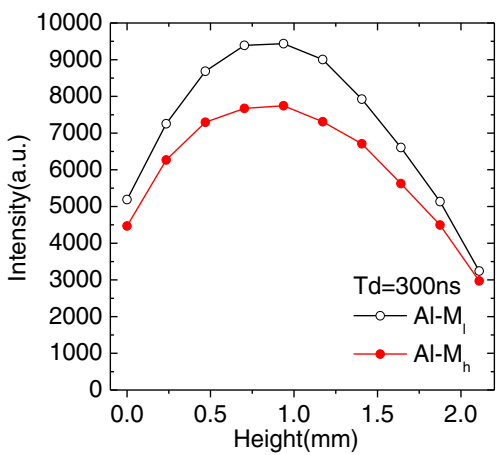

3b) $T_{d}=300 n s$

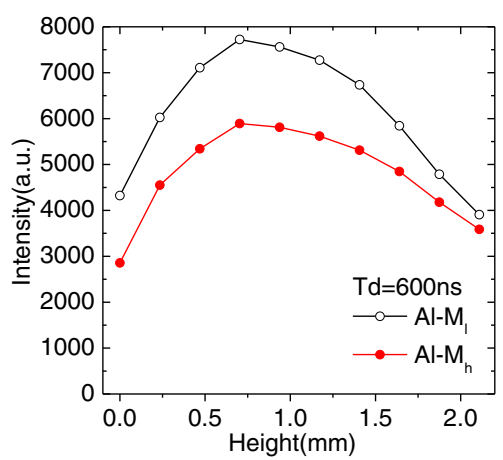

3c) $T_{d}=600 \mathrm{~ns}$

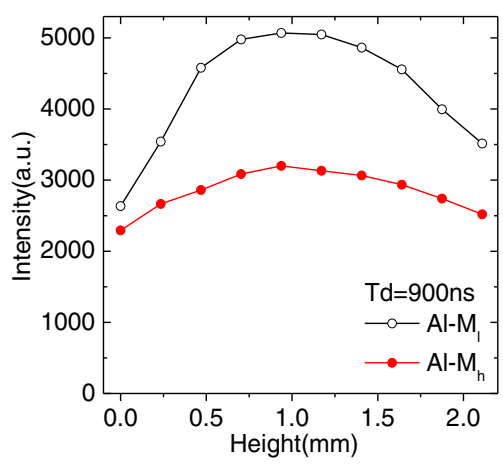

3d) $T_{d}=900 \mathrm{~ns}$

Fig. 9. Spatially resolved intensity as a function of the axial distance for 1) line H (I) $656.25 \mathrm{~nm}, 2$ ) C (I) $193.09 \mathrm{~nm}$, and 3) Al (I) $237.31 \mathrm{~nm}$ at different delay times.

reflection. The lower laser energy absorption made the less effective ablation coal mass and smaller line intensity. Moreover, the decrease in the $\mathrm{H}$ line intensity may be caused by the fact that water vapor containing $\mathrm{H}$ and $\mathrm{O}$ was pushed to the outside cooler layer of the plasma. The higher RSDs could be due to the unpredictable earlier moisture evaporation process and large fluctuations in the plasma morphology and properties. Our results also showed that the SNRs and SBRs of the line intensities decreased with increasing moisture content, which is useful information for the quantitative analysis of the coal moisture content. 


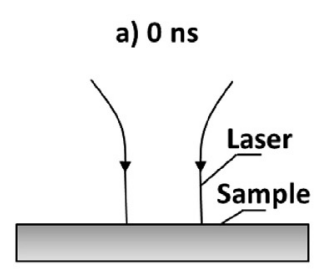

e) $800 \mathrm{~ns}$

b) $<<1$ ns

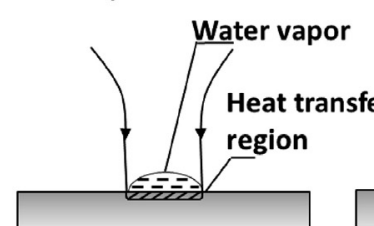

f) 1-2 $\mu \mathrm{s}$
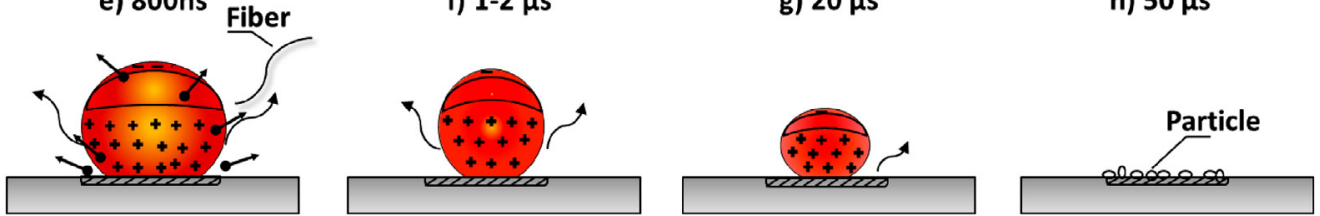

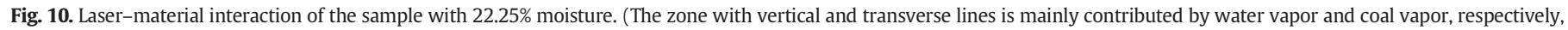
and the shaded zone is contributed by both water and coal vapor.)

a)

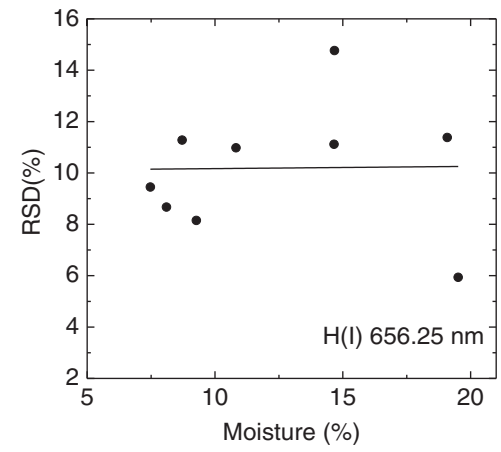

b)

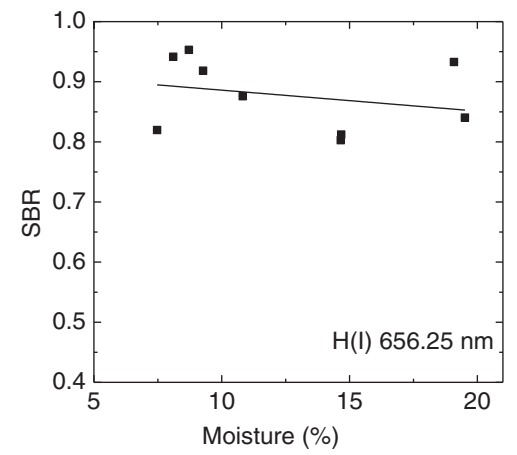

c)

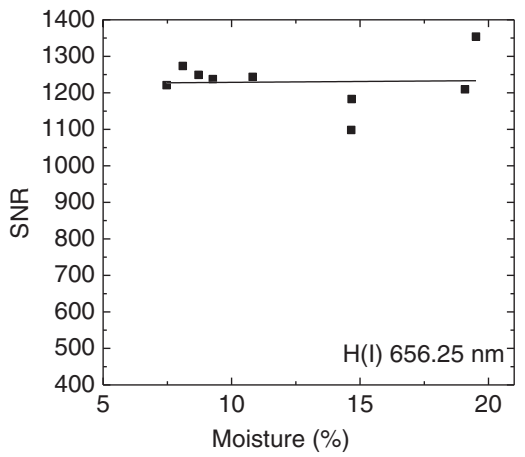

d)

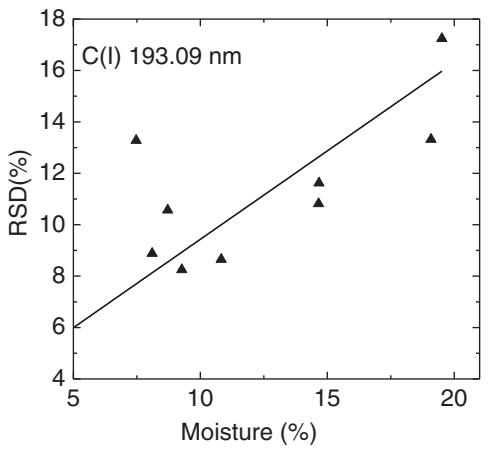

e)

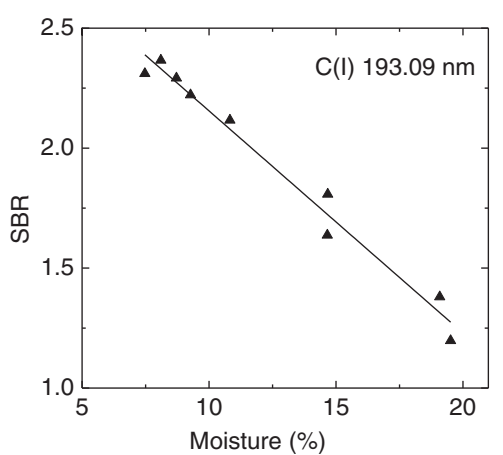

f)

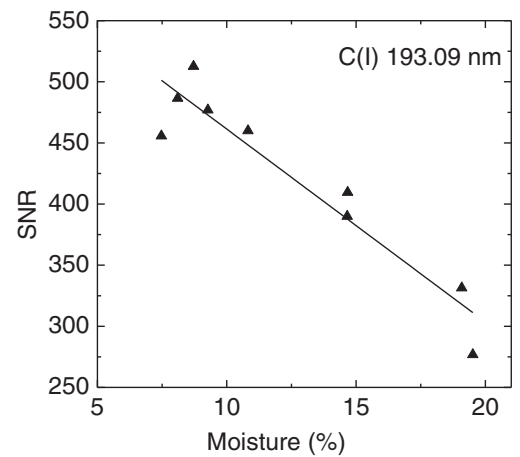

g)

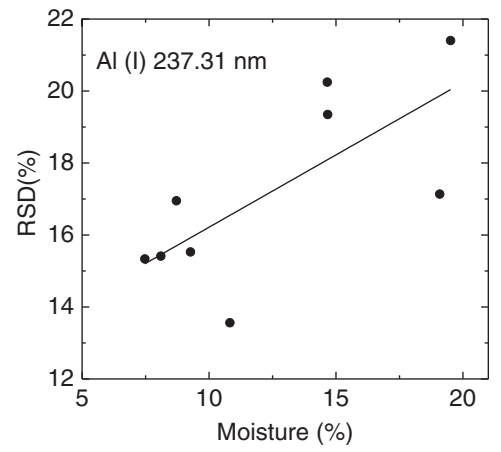

h)

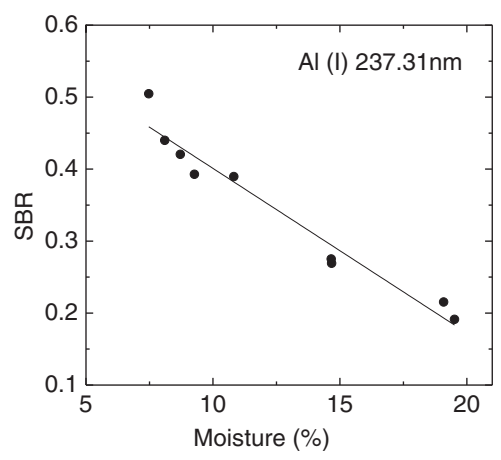

i)

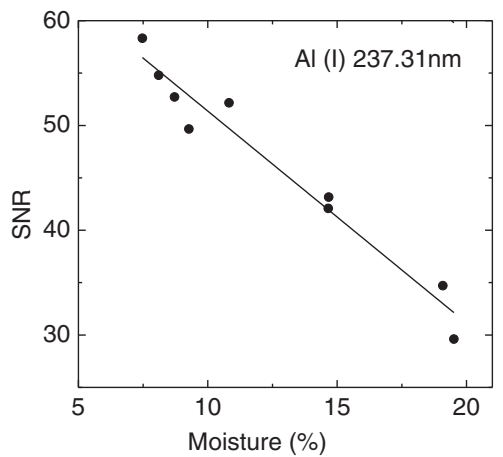

Fig. 11. RSD, SBR, and SNR of line H (I) $656.25 \mathrm{~nm}, \mathrm{C}$ (I) $193.09 \mathrm{~nm}$, and $\mathrm{Al}$ (I) $237.31 \mathrm{~nm}$. 
Table 3

Brief summary of current research together with literature work on the moisture influence for LIBS analysis.

\begin{tabular}{|c|c|c|c|c|}
\hline Parameter & Variation with increasing moisture & Experimental & Ref & Line chosen \\
\hline \multirow[t]{13}{*}{ Integrated intensity } & Decrease & $\begin{array}{l}\mathrm{CaCO}_{3} \text { powder }+ \text { water } \\
\mathrm{T}_{\mathrm{d}}=1 \mu \mathrm{s}, \mathrm{T}_{\mathrm{g}}=1 \mu \mathrm{s}\end{array}$ & {$[18]$} & $\mathrm{Ca}(\mathrm{II}) 393 \mathrm{~nm}$ \\
\hline & Decrease & Soil + water & [19] & $\mathrm{Cr}: \mathrm{N} A$ \\
\hline & & $\mathrm{T}_{\mathrm{d}}=1 \mu \mathrm{s}, \mathrm{T}_{\mathrm{g}}=1 \mu \mathrm{s}$ & & \\
\hline & Decrease & Soil $+\mathrm{PbNO}_{3}$ solution & {$[20]$} & $\mathrm{Pb}(\mathrm{I}) 405.78 \mathrm{~nm}$ \\
\hline & & $\mathrm{T}_{\mathrm{d}}=1.4 \mu \mathrm{s}, \mathrm{T}_{\mathrm{g}}=1 \mu \mathrm{s}$ & & \\
\hline & Decrease & As-received coal and air-dried coal & {$[21]$} & C (I) $247.86 \mathrm{~nm}$ \\
\hline & & $\mathrm{T}_{\mathrm{d}}=0.08 / 0.5 / 0.92 / 1.29 \mu \mathrm{s}, \mathrm{T}_{\mathrm{g}}=2 \mathrm{~ms}$ & & $\mathrm{Si}$ (I) $390.55 \mathrm{~nm}$ \\
\hline & Decrease & Air-dried coal + water & / & $\mathrm{H}(\mathrm{I}) 656.25 \mathrm{~nm}$ \\
\hline & & $\mathrm{T}_{\mathrm{d}}=1 \mu \mathrm{s}, \mathrm{T}_{\mathrm{g}}=1 \mathrm{~ms}$ & & C (I) $193.09 \mathrm{~nm}$ \\
\hline & & & & $\mathrm{Al}(\mathrm{I}) 237.31 \mathrm{~nm}$ \\
\hline & & & & $\mathrm{Si}(\mathrm{I}) 250.69 \mathrm{~nm}$ \\
\hline & & & & $\mathrm{Fe}(\mathrm{I}) 252.28 \mathrm{~nm}$ \\
\hline & & & & $\mathrm{O}(\mathrm{I}) 844.64 \mathrm{~nm}$ \\
\hline \multirow[t]{2}{*}{ Intensity evolution } & $\mathrm{H}$ : higher at initial time ( $<1 \mu \mathrm{s})$ and decay faster after $1 \mu \mathrm{s}$ & Air-dried coal + water & / & $\mathrm{H}(\mathrm{I}) 656.25 \mathrm{~nm}$ \\
\hline & $\mathrm{C}$ and $\mathrm{Al}$ : always lower & $\mathrm{T}_{\mathrm{d}}=0-4 \mu \mathrm{s}, \mathrm{T}_{\mathrm{g}}=1 \mathrm{~ms}$ & & $\begin{array}{l}\mathrm{C} \text { (I) } 193.09 \mathrm{~nm} \\
\mathrm{Al} \text { (I) } 237.31 \mathrm{~nm}\end{array}$ \\
\hline \multirow[t]{2}{*}{ Spatially resolved intensity } & Higher peak position of $\mathrm{H}$ along the height of plasma & Air-dried coal + water & / & $\mathrm{H}(\mathrm{I}) 656.25 \mathrm{~nm}$ \\
\hline & & $\mathrm{T}_{\mathrm{d}}=0-4 \mu \mathrm{s}, \mathrm{T}_{\mathrm{g}}=100 \mathrm{~ns}$ & & $\begin{array}{l}\text { C (I) } 193.09 \mathrm{~nm} \\
\mathrm{Al} \text { (I) } 237.31 \mathrm{~nm}\end{array}$ \\
\hline \multirow[t]{8}{*}{$\mathrm{T}$} & Unchanged & $\mathrm{CaCO}_{3}$ powder + water & {$[18]$} & \\
\hline & & $\mathrm{T}_{\mathrm{d}}=1 \mu \mathrm{s}, \mathrm{T}_{\mathrm{g}}=1 \mu \mathrm{s}$ & & \\
\hline & Decrease & Soil $+\mathrm{PbNO}_{3}$ solution & {$[19]$} & \\
\hline & & $\mathrm{T}_{\mathrm{d}}=1.4 \mu \mathrm{s}, \mathrm{T}_{\mathrm{g}}=1 \mu \mathrm{s}$ & & \\
\hline & Decrease & As-received coal and Air-dried coal & {$[21]$} & \\
\hline & & $\mathrm{T}_{\mathrm{d}}=0.08 / 0.5 / 0.92 / 1.29 \mu \mathrm{s}, \mathrm{T}_{\mathrm{g}}=2 \mathrm{~ms}$ & & \\
\hline & Unchanged & Air-dried coal + water & / & \\
\hline & & $\mathrm{T}_{\mathrm{d}}=0-4 \mu \mathrm{s}, \mathrm{T}_{\mathrm{g}}=1 \mathrm{~ms}$ & & \\
\hline \multirow[t]{8}{*}{$\mathrm{n}_{\mathrm{e}}$} & Decrease & $\mathrm{CaCO}_{3}$ powder + water & {$[18]$} & \\
\hline & & $\mathrm{T}_{\mathrm{d}}=1 \mu \mathrm{s}, \mathrm{T}_{\mathrm{g}}=1 \mu \mathrm{s}$ & & \\
\hline & Decrease & Soil $+\mathrm{PbNO}_{3}$ solution & {$[20]$} & \\
\hline & & $\mathrm{T}_{\mathrm{d}}=1.4 \mu \mathrm{s}, \mathrm{T}_{\mathrm{g}}=1 \mu \mathrm{s}$ & & \\
\hline & Unchanged & As-received coal and Air-dried coal & {$[21]$} & \\
\hline & & $\mathrm{T}_{\mathrm{d}}=0.08 / 0.5 / 0.92 / 1.29 \mu \mathrm{s}, \mathrm{T}_{\mathrm{g}}=2 \mathrm{~ms}$ & & \\
\hline & Increase before $1 \mu \mathrm{s}$ and then become unchanged & Air-dried coal + water & / & \\
\hline & & $\mathrm{T}_{\mathrm{d}}=0-4 \mu \mathrm{s}, \mathrm{T}_{\mathrm{g}}=1 \mathrm{~ms}$ & & \\
\hline \multirow[t]{4}{*}{ Plasma image } & Smaller plasma size & Air-dried coal + water & / & \\
\hline & Shorter life time & $\mathrm{T}_{\mathrm{d}}=0-1 \mu \mathrm{s}, \mathrm{T}_{\mathrm{g}}=100 \mathrm{~ns}$ & & \\
\hline & Lower intensity & & & \\
\hline & More inhomogeneous & & & \\
\hline \multirow[t]{2}{*}{ Ablation mass } & Larger total ablated mass but smaller effective ablated mass & Air-dried coal + water & / & \\
\hline & More dust on the surface after ablation & $\mathrm{T}_{\mathrm{d}}=1 \mu \mathrm{s}, \mathrm{T}_{\mathrm{g}}=1 \mathrm{~ms}$ & & \\
\hline \multirow[t]{3}{*}{ RSD } & Increase & Air-dried coal + water & / & $\mathrm{H}(\mathrm{I}) 656.25 \mathrm{~nm}$ \\
\hline & & $\mathrm{T}_{\mathrm{d}}=1 \mu \mathrm{s}, \mathrm{T}_{\mathrm{g}}=1 \mathrm{~ms}$ & & C (I) $193.09 \mathrm{~nm}$ \\
\hline & & & & $\mathrm{Al}(\mathrm{I}) 237.31 \mathrm{~nm}$ \\
\hline \multirow[t]{2}{*}{ SNR } & Decrease & Air-dried coal + water & / & $\mathrm{H}(\mathrm{I}) 656.25 \mathrm{~nm}$ \\
\hline & & $\mathrm{T}_{\mathrm{d}}=1 \mu \mathrm{s}, \mathrm{T}_{\mathrm{g}}=1 \mathrm{~ms}$ & & $\begin{array}{l}\text { C (I) } 193.09 \mathrm{~nm} \\
\mathrm{Al} \text { (I) } 237.31 \mathrm{~nm}\end{array}$ \\
\hline \multirow[t]{3}{*}{ SBR } & Decrease & Air-dried coal + water & / & $\mathrm{H}$ (I) $656.25 \mathrm{~nm}$ \\
\hline & & $\mathrm{T}_{\mathrm{d}}=1 \mu \mathrm{s}, \mathrm{T}_{\mathrm{g}}=1 \mathrm{~ms}$ & & C (I) $193.09 \mathrm{~nm}$ \\
\hline & & & & $\mathrm{Al}$ (I) $237.31 \mathrm{~nm}$ \\
\hline
\end{tabular}

Abbreviations: Ref, reference; N/A, not available; /, present work; $\mathrm{T}_{\mathrm{d}}$, delay time; $\mathrm{T}_{\mathrm{g}}$, gate time.

\section{Acknowledgment}

The authors are grateful for the financial support from the National Natural Science Foundation of China (No. 51276100) and National Basic Research Program (973 Program) of China (No. 2013CB228501).

\section{References}

[1] M. Gaft, I. Sapir-Sofer, H. Modiano, R. Stana, Laser induced breakdown spectroscopy for bulk minerals online analyses, Spectrochim. Acta Part B 62 (2007) 1496-1503.

[2] Z. Wang, T.-B. Yuan, Z.-Y. Hou, W.-D. Zhou, J.-D. Lu, H.-B. Ding, X.-Y. Zeng, Laser-induced breakdown spectroscopy in China, Front. Phys. 9 (2014) 419-438.

[3] F.J. Wallis, B.L. Chadwick, R.J.S. Morrison, Analysis of lignite using laser-induced breakdown spectroscopy, Appl. Spectrosc. 54 (2000) 1231-1235.

[4] X. Li, Z. Wang, Y. Fu, Z. Li, W. Ni, A model combining spectrum standardization and dominant factor based partial least square method for carbon analysis in coal using laser-induced breakdown spectroscopy, Spectrochim. Acta Part B 99 (2014) 82-86.

[5] T. Yuan, Z. Wang, Z. Li, W. Ni, J. Liu, A partial least squares and wavelet-transform hybrid model to analyze carbon content in coal using laser-induced breakdown spectroscopy, Anal. Chim. Acta 807 (2014) 29-35.
[6] M. Dong, J. Lu, S. Yao, J. Li, J. Li, Z. Zhong, W. Lu, Application of LIBS for direct determination of volatile matter content in coal, J. Anal. At. Spectrom. 26 (2011) 2183-2188.

[7] T. Yuan, Z. Wang, S.-L. Lui, Y. Fu, Z. Li, J. Liu, W. Ni, Coal property analysis using laser-induced breakdown spectroscopy, J. Anal. At. Spectrom. 28 (2013) 1045-1053.

[8] J. Li, J. Lu, Z. Lin, S. Gong, C. Xie, L. Chang, L. Yang, P. Li, Effects of experimental parameters on elemental analysis of coal by laser-induced breakdown spectroscopy, Opt. Laser Technol. 41 (2009) 907-913.

[9] T. Yuan, Z. Wang, L. Li, Z. Hou, Z. Li, W. Ni, Quantitative carbon measurement in anthracite using laser-induced breakdown spectroscopy with binder, Appl. Opt. 51 (2012) B22-B29.

[10] J. Feng, Z. Wang, Z. Li, W. Ni, Study to reduce laser-induced breakdown spectroscopy measurement uncertainty using plasma characteristic parameters, Spectrochim. Acta Part B 65 (2010) 549-556.

[11] X. Li, Z. Wang, Y. Fu, Z. Li, J. Liu, W. Ni, Application of a spectrum standardization method for carbon analysis in coal using laser-induced breakdown spectroscopy (LIBS), Appl. Spectrosc. 68 (2014) 955-962.

[12] J. Feng, Z. Wang, L. Li, Z. Li, W. Ni, A nonlinearized multivariate dominant factor-based partial least squares (PLS) model for coal analysis by using laser-induced breakdown spectroscopy, Appl. Spectrosc. 67 (2013) 291-300.

[13] M. Gaft, E. Dvir, H. Modiano, U. Schone, Laser induced breakdown spectroscopy machine for online ash analyses in coal, Spectrochim. Acta Part B 63 (2008) 1177-1182. 
[14] D. Body, B.L. Chadwick, Simultaneous elemental analysis system using laser induced breakdown spectroscopy, Rev. Sci. Instrum. 72 (2001) 1625-1629.

[15] J. Feng, Z. Wang, L. West, Z. Li, W. Ni, A PLS model based on dominant factor for coal analysis using laser-induced breakdown spectroscopy, Anal. Bioanal. Chem. 400 (2011) 3261-3271.

[16] D.A. Cremers, L.J. Radziemski, Qualitative LIBS analysis, Handbook of Laser-Induced Breakdown Spectroscopy, John Wiley \& Sons Ltd 2013, pp. 151-183.

[17] H.R. Griem, Spectral Line Broadening by Plasma, Academic Press, New York, 1974.

[18] D.A. Rusak, M. Clara, E.E. Austin, K. Visser, R. Niessner, B.W. Smith, J.D. Winefordner, Investigation of the effect of target water content on a laser-induced plasma, Appl. Spectrosc. 51 (1997) 1628-1631.

[19] R.W. Wisbrun, I. Schechter, R. Niessner, H. Schroeder, Laser-induced breakdown spectroscopy for detection of heavy metals in environmental samples, 1993 2-15.
[20] C. Lu, W. Liu, N. Zhao, L. Liu, D. Chen, Y. Zhang, J. Liu, Influence of humidity on characteristic of laser-induced soil plasmas, Spectrosc. Spectr. Anal. 30 (2010) 2885-2888.

[21] P. Li, J. Lu, C. Xie, J. Li, Y. Liu, M. Jiang, M. Chen, Influence of moisture on plasma characters of laser-induced pulverized coal, Chin. J. Lasers 36 (2009) 828-832.

[22] N. Reinhard, Laser-Induced Breakdown Spectroscopy: Fundamentals and Applications, Springer, Germany, 2012.

[23] LC. Jensen, S.C. Langford, J.T. Dickinson, R.S. Addleman, Mechanistic studies of laser-induced breakdown spectroscopy of model environmental samples, Spectrochim. Acta Part B 50 (1995) 1501-1519. 